\title{
Ecological Evaluation of Industrial Parks Using a Comprehensive DEA and Inverted-DEA Model
}

\author{
Bingjiang Zhang, ${ }^{1}$ Jinling Guo, ${ }^{1}$ Zheng Wen, ${ }^{1}$ Zhaoyao Li, ${ }^{1}$ and Ning Wang $\mathbb{D}^{1,2,3}$ \\ ${ }^{1}$ Beijing Information Science and Technology University, Beijing 100192, China \\ ${ }^{2}$ Beijing Key Lab of Green Development Decision Making Based on Big Data, Beijing 100192, China \\ ${ }^{3}$ Beijing Knowledge Management Research Center, Beijing 100192, China \\ Correspondence should be addressed to Ning Wang; wn@bistu.edu.cn
}

Received 17 August 2020; Accepted 26 October 2020; Published 10 November 2020

Academic Editor: Akemi Gálvez

Copyright ( 92020 Bingjiang Zhang et al. This is an open access article distributed under the Creative Commons Attribution License, which permits unrestricted use, distribution, and reproduction in any medium, provided the original work is properly cited.

\begin{abstract}
Data envelopment analysis (DEA) and inverted data envelopment analysis (inverted-DEA) are used so that the desirable and undesirable outputs of decision-making units (DMUs) exist simultaneously. We developed a new approach based on the concept of utilizing both DEA and inverted-DEA to enhance the discrimination power of DMUs with undesirable outputs. DMUs are ranked by the $Z$-score method and classified based on the efficiency scores of DEA and inverted-DEA. Then, the characteristics of the DMUs are analyzed based on the classification result. This paper performs an efficiency evaluation of 21 industrial parks in China in 2017 using this new approach. The overall evaluation results indicate that the proposed new approach increases the discrimination ability in this empirical study.
\end{abstract}

\section{Introduction}

Data envelopment analysis (DEA) was proposed by three operational research experts, A. Charnes, W. Cooper, and E. Rhodes, in 1978 [1]. DEA is a new systematic analysis method used for evaluating the efficiency of similar decisionmaking units (DMUs) with multiple inputs and outputs. This method does not need to restrict the production function and can avoid the subjective decision and objective factor dimensionality, and the impact of a unit's impact on evaluation results [2]. The classic DEA models first identify the production frontier for which the DMUs can be regarded as efficient. DMUs, which are outliers in terms of low inputs relative to the output level, map the efficient frontier. The DMUs on the frontier are efficient, and the DMUs not on the frontier are inefficient. Those inefficient DMUs are compared with efficient DMUs to estimate their efficiency scores. DEA provides users with information about the efficiency scores and inefficiency scores and reference sets for inefficient units. One of the main features of DEA is to allow the DMUs to select their weights, which is a favorable approach for achieving maximum efficiency scores. However, this full flexibility may considerably reduce the discrimination power of DEA in the sense that too many DMUs often exist on the frontier, and some DMUs cannot be further ranked in standard DEA models.

To solve this problem, Allen et al. studied weight constraints and value judgments and concentrated on the implications of weight restrictions on the efficiency, targets, and comparisons of inefficient DMUs in DEA [3]. Additionally, Andersen and Petersen [4] employed a superefficiency DEA model to evaluate efficient DMUs; the model excludes the DMU being evaluated from the reference set. This model was first used to identify outliers of observations by Banker and Gillord [5]. The model uses different reference sets to evaluate efficient and inefficient DMUs. Furthermore, Banker and Chang [6] reported that Andersen and Petersen's [4] procedure using superefficiency scores to rank efficiency observations yielded poor performance. Some scholars have tried to solve problems by using cross- 
efficiency methods. In such approaches, DMUs are evaluated based on their characteristics and those of other DMUs using a cross-efficiency matrix [7, 8]. Although the crossefficiency method is often beneficial, the concept of crossefficiency score methods is considerabe from the basic principle of DEA.

Additionally, some scholars have attempted to construct new evaluation methods using DEA and inverted-DEA models. Amirteimoori [9] proposed the production possibility set and the quasi-production possibility set and constructed an alternative efficiency measure by using an efficiency frontier composed of the boundary points of the production possibility set and an antiefficient frontier composed of the boundary points of the quasi-production possibility set. However, this approach failed to solve the identification problem that occurs when many DMUs are efficient or inefficient. Zhang et al. [10] proposed an evaluation model of DMUs by using a good reference set and a bad reference set from the best and worst perspectives. To obtain the bad reference set, they simply treated the inputs and outputs of DMUs as undesirable. Cao et al. [11] used the evidential-reasoning (ER) approach to construct a performance indicator for combining the efficiency and antiefficiency values obtained by DEA and inverted-DEA models. Zhou et al. [12] used a DEA model without explicit inputs (see, e.g., Liu et al. [13], Liu et al. [14], and Yang et al. [15]) to combine efficient and antiefficient measures to rank DMUs. However, Shen et al. [16] easily verified that their approach could not significantly increase the discrimination power of DEA models and constructed three intuitive DEA performance indicators based on the distances to both the efficient and antiefficient frontiers. Although each performance indicator is useful for a specific sample size, no one approach can be referred to as a complete solution to all problems.

Furthermore, Entani et al. [17] employed both DEA and inverted-DEA models to obtain the upper and lower bounds of the interval efficiency of DMUs. They argued that if the range of the interval efficiency is broad, then although the DMUs perform well from an optimistic perspective, they perform poorly from a pessimistic perspective. Then, they used the interval efficiency to obtain a partial-order relation for DMUs. Thus, there has been a lack of clear distinctions among evaluations, and explicitly, certain information is difficult to obtain, providing little practical help to decisionmakers.

While the abovementioned techniques are useful in specific research areas, no one method provides a complete solution for all problems. People often have more than one reference perspective in assessing DMUs. The standard DEA models have employed the best-practice DMUs to construct the efficient frontier and have not fully taken advantage of the information implied in the data, especially for DMUs with undesirable outputs. In this paper, we explore a concept that involves enhancing the discrimination ability of DEA. In the case of the same inputs, the DEA model and the inverted-DEA model are used to enhance the discrimination ability of DMUs with desirable outputs and DMUs with undesirable outputs, respectively. The earliest work on the antiefficient frontier can be traced to the inverted-DEA model proposed by Yamada et al. [18]. Compared to the standard DEA models that evaluate DMUs from the perspective of optimism, the inverted-DEA model evaluates the performance from pessimism.

The DEA method is not affected by the input and output dimensions of the problem and can comprehensively evaluate the data of different indicators. In particular, this approach has distinct advantages in dealing with multiple inputs and multiple outputs. However, most of the problems addressed with traditional DEA models have assumed that inputs and outputs are arbitrarily determined, the management activities of DMUs are controllable, and the output of DMUs should be optimized. However, in the actual production process, desirable and undesirable outputs may exist simultaneously. For example, a defective product is an undesirable output. In industrial production, economic benefits will also result in pollution, such as waste or smoke pollution, which is an undesirable output [19]. If the production processes that yield final products that generate wastes and pollutants are inefficient, the waste and pollutant outputs will be undesirable and should be reduced to improve performance. However, some wastes and pollutants are inevitably produced and cannot be reduced. Thus, the typical assumption of DEA is invalid. As a result, the undesirable and desirable outputs should be differently treated when DEA is used to evaluate the performance of DMUs. The most common approach is to consider only desirable outputs and ignore undesirable outputs [20]. However, such an evaluation method is overly simple and ignores essential information. Therefore, performance evaluations based on such methods are not comprehensive.

Some researchers have suggested that some undesirable variables can be transformed [21]. For example, the ADD method proposed by Koopmans multiplies the undesirable output by -1 [19]. Similarly, it is also possible to add a translation vector based on negative transformations to keep the output data nonnegative [22]. Additionally, undesirable variables can be transformed nonlinearly, such as by multiplicative inverse operations [18]. However, these transformation methods may produce some unfavorable results [23]. Notably, transformations are often nonlinear and cannot retain convexity. In addition to applying transformation methods, undesirable outputs can also be regarded as inputs. If one treats the undesirable outputs as inputs, although the method is simple and easy to implement, the resulting DEA model does not reflect the actual production process. Additionally, the constraint function in linear programming can be adjusted, that is, the desirable and undesirable outputs classified, the output constraint function of the traditional DEA model is divided into two functions, and the desirable and undesirable outputs are constrained [24]. Furthermore, the distance measure can be adjusted to limit the range of undesirable outputs.

The methods mentioned above for dealing with undesirable outputs in DEA mostly involve adjusting variables or models; notably, in the traditional model, undesirable outputs are processed through mathematical methods, but this approach does not reflect the actual situation. In this 
paper, we consider using an inverted-DEA to process undesirable outputs. Japanese scholar Yamada et al. proposed inverted-DEA in 1994 to evaluate the inefficiency score of DMUs, which is contrary to the concept of efficiency in DEA. When a DMU is inefficient, the model considers decreasing the output level and increasing the input level to improve efficiency, which reflects the objective of minimizing undesirable outputs under actual conditions. Therefore, the use of an inverted-DEA model to address undesirable outputs can reflect the actual production process and is more straightforward and reasonable than other methods.

The remainder of the paper is organized as follows. In Section 2, we present a comprehensive evaluation method for DMUs utilizing both DEA and inverted-DEA. Section 3 discussed a category analysis of DMUs. Section 4 applied the proposed method to an empirical data set consisting of 21 industrial parks in China in 2017. Finally, the discussion and conclusions are given in Section 5.

\section{Methods}

2.1. DEA. DEA is an approach for analyzing the relative efficiency of peer DMUs that have multiple inputs and outputs. The evaluation of the DMU's efficiency is carried out by measuring the distance of this unit from the efficiency frontier created on the basis of the best units in the group, serving as benchmarks. In DEA, the maximum ratio of outputs is assumed to be efficiency, which is calculated from the optimistic perspective for each DMU. The efficiency for $\mathrm{DMU}_{0}$, which is analyzed as an object, is evaluated based on the efficiency values of the other DMUs. The following basic DEA model evaluates the efficiency of $\mathrm{DMU}_{0}$ with $s$ dimensional input vectors and $m$ dimensional output vectors:

$$
\begin{aligned}
& \max \frac{\mathbf{u}^{T} \mathbf{y}_{0}}{\mathbf{v}^{T} \mathbf{x}_{0}} \\
& \text { s.t. } \frac{\mathbf{u}^{T} \mathbf{y}_{j}}{\mathbf{v}^{T} \mathbf{x}_{j}} \leq 1, \quad j=1,2, \ldots, n, \mathbf{u} \geq 0, \mathbf{v} \geq 0,
\end{aligned}
$$

where the decision variables are the weight vectors $\mathbf{u}$ and $\mathbf{v}$; $\mathbf{x}_{j}$ and $\mathbf{y}_{j}$ are the input and output vectors for $\mathrm{DMU}_{j}$, respectively; and $\mathbf{x}_{0}$ and $\mathbf{y}_{0}$ are the input and output vectors for $\mathrm{DMU}_{0}$ under evaluation, respectively. Each element of $\mathbf{x}_{j}$ and $\mathbf{y}_{j}$ is positive. To address many inputs and outputs, we consider the weighted sums of inputs and outputs as a hypothetical input and a hypothetical output. The efficiency is obtained by maximizing the ratio of weighted sum of outputs to that of inputs for $\mathrm{DMU}_{0}$ under the condition that ratios for all DMUs are less than or equal to 1 .

This fractional programming problem is replaced with the following LP problem, which is called the $C^{2} \mathrm{R}$ model, by limiting the denominator of the objective function to 1 :

$$
\begin{array}{cl} 
& \max \quad \mathbf{u}^{T} \mathbf{y}_{0} \\
& \\
& \frac{\mathbf{u}^{T} \mathbf{y}_{j}}{\mathbf{v}^{T} \mathbf{x}_{j}} \leq 1, \quad j=1,2, \ldots, n \\
\text { s.t. } & \\
& \mathbf{v}^{T} \mathbf{x}_{0}=1 \\
& \\
& \mathbf{u} \geq 0, \mathbf{v} \geq 0 .
\end{array}
$$

For which the LP dual problem is

$$
\begin{aligned}
\min & \theta \\
& \lambda^{T} \mathbf{x}_{j} \leq \theta \mathbf{x}_{0}, \quad j=1,2, \ldots, n \\
\left(\mathrm{D}_{\mathrm{C}^{2} \mathrm{R}}\right) & \\
& \lambda^{T} \mathbf{y}_{j} \geq \mathbf{y}_{0}, \quad j=1,2, \ldots, n \\
& \lambda \geq 0, \boldsymbol{\lambda} \neq 0 .
\end{aligned}
$$

When the optimal value of the objective function is equal to $1, \mathrm{DMU}_{0}$ is considered efficient, and otherwise, it is not deemed efficient. Specifically, "efficient" in this paper includes "weakly efficient."

If we consider the slacks of inputs and outputs, we can then introduce the variables $s_{i}^{-}$and $s_{r}^{+}$and transform model (3) into the following model:

$$
\begin{aligned}
& \min \quad \theta-\varepsilon\left(\sum_{r=1}^{s} s_{r}^{+}+\sum_{i=1}^{m} s_{i}^{-}\right) \\
& \sum_{j=1}^{n} \lambda_{j} x_{i j}+s_{i}^{-}=\theta x_{i 0}, \quad i=1,2, \ldots, m \\
&\left(\mathrm{D}_{\mathrm{C}^{2} \mathrm{R}}\right) \quad \sum_{j=1}^{n} \lambda_{j} y_{r j}-s_{r}^{+}=y_{r 0}, \quad r=1,2, \ldots, s \\
& \text { s.t. } \quad \lambda_{j} \geq 0, \quad j=1,2, \ldots, n \\
& s_{r}^{+} \geq 0, s_{i}^{-} \geq 0, r=1,2, \ldots, s, i=1,2, \ldots, m,
\end{aligned}
$$

where $\varepsilon$ is a non-Archimedean infinitesimal and $\theta$ is the DEA efficiency score.

Definition 1. A DMU 0 is said to be DEA efficient if and only if (a) $\theta^{*}=1$ and (b) all optimum slack values in equation (4) are zero.

2.2. Inverted-DEA. Since the inverted-DEA was first proposed in Japanese [18], we will illustrate the inverted-DEA method here. In contrast to DEA, which evaluates $\mathrm{DMU}_{0}$ from the optimistic perspective, inverted-DEA is formulated as follows: 


$$
\begin{aligned}
& \max \frac{\mathbf{v}^{T} \mathbf{x}_{0}}{\mathbf{u}^{T} \mathbf{y}_{0}} \\
& \text { s.t. } \frac{\mathbf{v}^{T} \mathbf{x}_{j}}{\mathbf{u}^{T} \mathbf{y}_{j}} \leq 1, \quad j=1,2, \ldots, n \\
& \quad \mathbf{u} \geq 0, \mathbf{v} \geq 0 .
\end{aligned}
$$

This fractional programming problem is also replaced with the following LP problem:

$$
\begin{aligned}
& \max \mathbf{v}^{T} \mathbf{x}_{0} \\
& \text { s.t. } \frac{\mathbf{v}^{T} \mathbf{x}_{j}}{\mathbf{u}^{T} \mathbf{y}_{j}} \leq 1, \quad j=1,2, \ldots, n \\
& \mathbf{u}^{T} \mathbf{y}_{0}=1 \\
& \mathbf{u} \geq 0, \mathbf{v} \geq 0 .
\end{aligned}
$$

By using the duality principle of linear programming, model (6) can be equivalently changed into the following linear programming model:

$$
\begin{array}{ll}
\min \theta^{\prime} & \\
\text { s.t. } & \lambda^{\prime T} \mathbf{y}_{j} \leq \theta^{\prime} \mathbf{y}_{0}, \quad j=1,2, \ldots, n \\
& \lambda^{\prime T} \mathbf{x}_{j} \geq \mathbf{x}_{0}, \quad j=1,2, \ldots, n \\
& \lambda^{\prime} \geq 0, \lambda^{\prime} \neq 0,
\end{array}
$$

where $\theta^{\prime}$ represents the inverted-DEA inefficiency score of $\mathrm{DMU}_{0}$.

We can then introduce variables $s_{i}^{\prime}$ and $s_{r}^{\prime}$ and transform model (7) into the following model:

$$
\begin{aligned}
& \min \theta^{\prime}-\varepsilon\left(\sum_{r=1}^{s} s_{r}^{{ }^{+}}+\sum_{i=1}^{m} s_{i}^{\prime-}\right) \\
& \text { s.t. } \sum_{j=1}^{n} \lambda_{j}^{\prime} y_{r j}+s_{r}^{{ }^{+}}=\theta^{\prime} y_{r 0}, \quad r=1,2, \ldots, s \\
& \quad \sum_{j=1}^{n} \lambda_{j}^{\prime} x_{i j}-s_{i}^{\prime-}=x_{i 0}, \quad i=1,2, \ldots, m \\
& \lambda_{j}^{\prime} \geq 0, \quad j=1,2, \ldots, n \\
& s_{r}^{\prime} \geq 0, s_{i}^{\prime} \geq 0, r=1,2, \ldots, s, i=1,2, \ldots, m .
\end{aligned}
$$

Definition 2. A $\mathrm{DMU}_{0}$ is said to be inverted-DEA inefficient if and only if (a) $\theta^{\prime *}=1$ and (b) all optimum slack values in equation (8) are zero.

We use one-dimensional input and two-dimensional output data to illustrate the difference between DEA and inverted-DEA. Figure 1 shows the processed data, the efficient frontier based on DEA, and the inefficient frontier based on inverted-DEA.

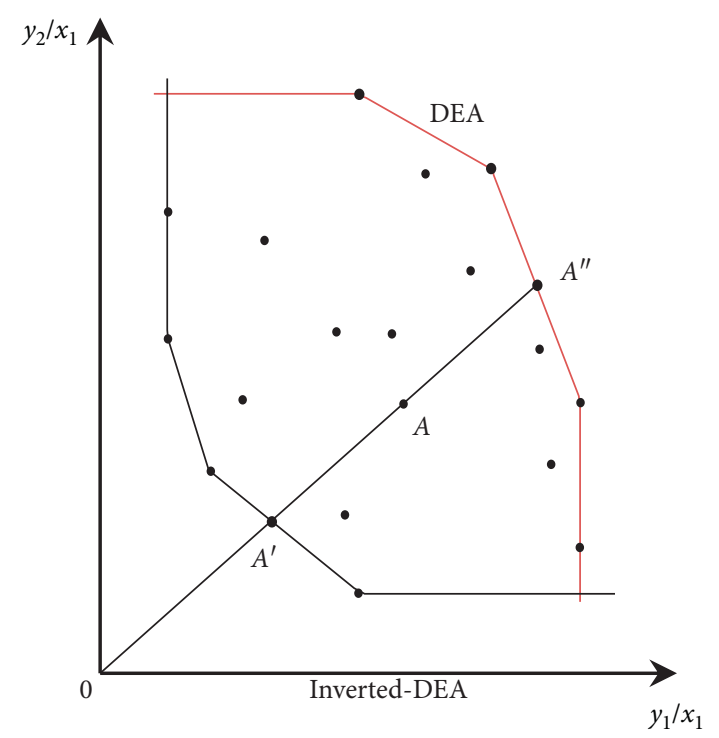

FIgURE 1: DEA and inverted-DEA.

2.3. Comprehensive Evaluation. Using the DEA model and inverted-DEA model, an efficiency analysis of DMUs is conducted with both desirable and undesirable outputs. Next, we will introduce four indicators (DEA analysis and inverted-DEA analysis for DMUs with inputs/desirable outputs and DEA analysis and inverted-DEA analysis for DMUs with inputs/undesirable outputs), which constitute a new efficiency measure, and rank DMUs according to this efficiency measure.

For $n$ production units, or DMUs, we denote the input vector of DMUj as $\mathbf{x}_{j}(j=1, \ldots, n)$, where $\mathbf{x}_{j} \in E^{m}$, and the output vectors of DMUj with desirable outputs and undesirable outputs as $\mathbf{y}_{j}^{g}$ and $\mathbf{y}_{j}^{b}$, where $\mathbf{y}_{j}^{g}, \mathbf{y}_{j}^{b} \in E^{s}$. We denote the efficiency scores of the DMUs with desirable outputs and undesirable outputs as $\theta^{g}$ and $\theta^{b}$, respectively. Similarly, we denote the inefficiency score of the DMUs with desirable outputs and the inefficiency score of the DMUs with undesirable outputs as $\theta^{\prime g}$ and $\theta^{\prime b}$, respectively.

Using model (4), the DEA efficiency scores of each DMU with desirable and undesirable outputs are calculated as $\theta^{g}$ and $\theta^{b}$, respectively. Similarly, by using model (8), the inverted-DEA inefficiency scores of each DMU with desirable and undesirable outputs are calculated as $\theta^{\prime g}$ and $\theta^{\prime b}$, respectively.

According to the properties of models (1) and (5), we obtain $0 \leq \theta^{g}, \theta^{b}, \theta^{\prime g}, \theta^{\prime b} \leq 1$. In the sense of evaluating the efficiency of DMUs, larger values of $\theta^{g}$ and $\theta^{\prime b}$ are preferred, and small values of $\theta^{b}$ and $\theta^{\prime g}$ are ideal. Thus, the new model is as follows:

$$
e_{0}=\frac{\theta^{g}{\theta^{\prime}}^{b}+\theta^{\prime b}\left(1-\theta^{\prime g}\right)+\left(1-\theta^{\prime g}\right)\left(1-\theta^{b}\right)+\left(1-\theta^{b}\right) \theta^{g}}{4}
$$

It can be verified that $e_{0}$ is invariant to the units of the data. Furthermore, it holds that $0 \leq e_{0} \leq 1$.

Based on the information above, we can obtain the following definitions. 
Definition 3. A DMU $\mathrm{DM}_{0}$ is full efficient if $e_{0}=1$.

Definition 4. A $\mathrm{DMU}_{0}$ is full inefficient if $e_{0}=0$.

The comprehensive evaluation index $e_{0}$ can increase the discrimination power of DEA. For example, if the index scores of a DMU are $\left(\theta^{g}, \theta^{b}, \theta^{\prime g}, \theta^{\prime b}\right)=(0.45,0.55,0.35,0.70)$, then $e_{0}=0.316$. Efficiencies and inefficiencies are shown in Figure 2. Each index score of a DMU is marked on the corresponding coordinate axis, and these points are connected to form a planar geometric graph. The corresponding shaded area of the graph is the comprehensive evaluation score of the DMU.

\section{Category Analysis of DMUs}

In the section, two critical steps are performed. First, all of the DMUs are categorized based on the ranks obtained with equation (9). Second, all of the DMUs are categorized by using $\theta^{g}, \theta^{b}, \theta^{\prime g}$, and $\theta^{\prime b}$.

To compare the production level of several production units under similar conditions, the same type of experiment for multiple production units must be performed to evaluate the production skills by comparing the results of the experiments. For such joint detection, an evaluation rule is required. A general evaluation rule is based on the following factors: (a) expert opinions; (b) rules confirmed by authoritative departments; and (c) minimizing the influence of extreme values.

In this paper, the results are compared by using the previous result set, which is the $Z$-score-based method of evaluation.

If the data of $z_{j}(j=1, \ldots, n)$ follow a normal distribution, the $Z$-score is calculated using the quartile method according to the following steps.

Step 1: rank the obtained sample $z_{j}(j=1, \ldots, n)$ by ascending sorting.

Step 2: obtain the values of a quarter of $z_{N 1}$ $(N 1=(n / 4)+0.5), \quad$ two quarters of $z_{N 2}$ $(N 2=(2 n / 4)+0.5)$ and three quarters of $z_{N 3}$ $(N 3=(3 n / 4)+0.5)$.

Step 3: calculate the $Z$-score of the measurement value $z_{j}$ according to

$$
Z_{j}=\frac{z_{j}-\mu}{\sigma}
$$

where $\mu$ is the criterion value and $\sigma$ is the standard deviation.

According to the relation of the standard deviation $\sigma$, quartile, and IQR (interquartile range), the following equation can be obtained:

$$
\mathrm{IQR}=\left(z_{N 3}-z_{N 1}\right)=2 \times 0.6745 \sigma=1.349 \sigma .
$$

Thus,

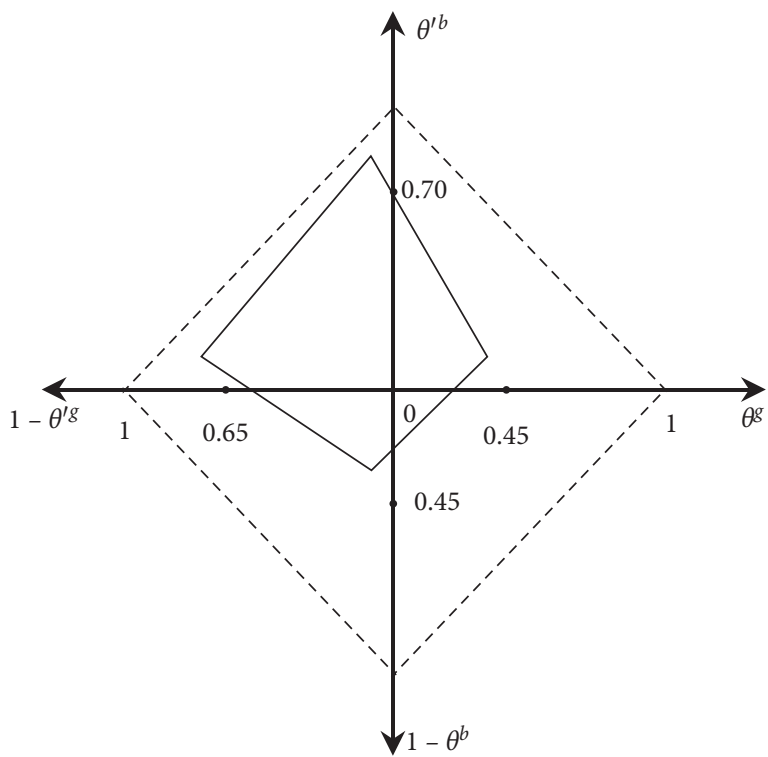

Figure 2: Efficiencies and inefficiencies for crisp data.

$$
\sigma=0.7413 \times \mathrm{IQR}=0.7413 \times\left(z_{N 3}-z_{N 1}\right) .
$$

In equation (10), if $\mu=z_{N 2}$, the $Z$-score of $z_{j}$ is as follows:

$$
Z_{j}=\frac{z_{j}-z_{N 2}}{0.7413 \times\left(z_{N 3}-z_{N 1}\right)} .
$$

Regarding the production units evaluated, we obtain two evaluation criteria based on equation (13) and $|Z|=3$ :

$$
\begin{gathered}
\bar{Z}=-2.2239\left(z_{N 3}-z_{N 1}\right)+z_{N 2}, \\
\widehat{Z}=2.2239\left(z_{N 3}-z_{N 1}\right)+z_{N 2}
\end{gathered}
$$

where $\bar{Z}$ and $\widehat{Z}$ are the reference values of $Z$-score $Z_{j}$ corresponding to $Z=-3$ and $Z=3$, respectively.

According to $\bar{Z}$ and $\widehat{Z}$, the $Z$-score can be divided into three categories: "excellent," "ordinary," and "pending improvement."

Next, we categorize all of the DMUs by using $\theta^{*}$ and $\theta^{\prime *}$. This category analysis includes analyzing DMUs with desirable outputs and undesirable outputs. The specific method involves finding the appropriate thresholds $\alpha$ and $\beta$ and dividing the DMUs into four categories according to the efficiency scores of DEA and inefficiency score of invertedDEA. The specific categories are shown in Table 1. For a DMU with desirable outputs and undesirable outputs, the category analysis based on DEA/inverted-DEA is shown in Figure 3.

According to the category analysis of DMUs based on DEA/inversed DEA, combined with the comprehensive score of DMUs obtained using $e_{0}$, the category of the DMU can be determined. 


\section{Case Study}

We use the DEA model and the inversed DEA model to calculate the efficiency and inefficiency scores of 21 industrial parks, all of which are the first batch of circular economy pilot parks in China in 2017. Relevant data of the study come from research reports and statistical yearbooks of the samples.

The input and output variables are defined as follows. The input variables are divided into four classes: resources $\left(X_{1}\right)$, energy $\left(X_{2}\right)$, land $\left(X_{3}\right)$, and water resources $\left(X_{4}\right)$. The output variables are divided into two classes: desirable outputs $(D)$ and undesirable outputs $(U)$. The desirable outputs include the resource output rate $\left(D_{1}\right)$ and total production value $\left(D_{2}\right)$, which reflect the economic output per unit input of material resources and the value of all final products and services produced by the park economy during a certain period. The undesirable outputs include sulfur dioxide emissions $\left(U_{1}\right)$, industrial solid waste emissions $\left(U_{2}\right)$, and industrial wastewater discharge $\left(U_{3}\right)$. This paper selects 21 industrial parks in China for analysis: the ZJ Technology Development Zone $\left(\mathrm{DMU}_{1}\right)$, BJ Technology Development Zone $\left(\mathrm{DMU}_{2}\right)$, LG Technology Development Zone $\left(\mathrm{DMU}_{3}\right)$, BX Technology Development Zone $\left(\mathrm{DMU}_{4}\right)$, $\mathrm{CF}$ Economic Development Zone $\left(\mathrm{DMU}_{5}\right), \mathrm{DH}$ Industrial Park $\left(\mathrm{DMU}_{6}\right)$, DY Technology Development Zone $\left(\mathrm{DMU}_{7}\right)$, GX Technology Development Zone $\left(\mathrm{DMU}_{8}\right)$, GA Technology Development Zone $\left(\mathrm{DMU}_{9}\right)$, GY Technology Development Zone $\left(\mathrm{DMU}_{10}\right)$, HN Industrial Park (DMU $\left.\mathrm{D}_{11}\right)$, $\mathrm{HB}$ Development Zone $\left(\mathrm{DMU}_{12}\right)$, JX Industrial Park $\left(\mathrm{DMU}_{13}\right), \mathrm{NB}$ Technology Development Zone (DMU 14 ), NX Economic Technology Development District (DMU ${ }_{15}$ ), QD Technology Development Zone $\left(\mathrm{DMU}_{16}\right)$, TJ Technology Development Zone $\left(\mathrm{DMU}_{17}\right)$, TL Technology Development Zone $\left(\mathrm{DMU}_{18}\right)$, WL Technology Development Zone $\left(\mathrm{DMU}_{19}\right)$, ZJT Industrial Park (DMU $\left.{ }_{20}\right)$, and CS Demonstration Base $\left(\mathrm{DMU}_{21}\right)$. The input and output data for 21 industrial parks in 2017 are shown in Table 2 .

According to the data from 21 industrial parks in Table 2 and model (4) and model (8), the relative efficiency scores and inefficiency scores of DMUs can be obtained (see Table 3).

As shown in Table 3, for the desirable outputs, the relative efficiency scores of nine DMUs have reached 1 for model (4); that is, nine DMUs are efficient based on DEA. Similarly, for the undesirable outputs, we have two inefficient DMUs based on the inverted-DEA and model (8). As the fourth and fifth columns of the table indicate, for the undesirable outputs, ten DMUs lie on the efficient frontier, so the efficiency scores of these units are equal to 1. Conversely, five DMUs lie on the antiefficient frontier, so the inefficiency scores of these units are equal to 1 . Among them, $\mathrm{DMU}_{2}$ and $\mathrm{DMU}_{10}$ are not only DEA efficient but also inverted-DEA inefficient, which means that these two DMUs have efficient economic outputs but also produce efficient waste discharge. Many DMUs exist on the frontier that cannot be further ranked in standard DEA models and the inverted-DEA model. Additionally, the DMUs on both frontiers will have the same
TABLE 1: Category analysis of DMUs.

\begin{tabular}{lcc}
\hline DMUs & Desirable outputs & Undesirable outputs \\
\hline$\theta^{*} \geq \alpha$ & Excellent DMUs & $\begin{array}{c}\text { Pending improvement } \\
\text { DMUs }\end{array}$ \\
$\theta^{\prime *} \leq \beta$ & Ordinary DMUs & Personality DMUs \\
\hline$\theta^{*}<\alpha$ & & \\
$\theta^{\prime *}<\beta$ & Ordinary DMUs \\
\hline$\theta^{*} \geq \alpha$ & Personality DMUs & \\
$\theta^{\prime *} \geq \beta$ & Excellent DMUs \\
\hline$\theta^{*}<\alpha$ & Pending improvement & DMUs \\
$\theta^{\prime *} \geq \beta$ & DMU
\end{tabular}

performance scores, which cannot be differentiated in traditional DEA methods.

To solve the above problem, we use the performance indicators proposed in Table 3 to calculate the comprehensive evaluation scores of 21 industrial parks based on model (9). The computed results are shown in Table 4.

To use the quartile method to categorize the data in Table 4, the distribution of these data must be analyzed. The analysis results are shown in Figure 4.

Because the comprehensive evaluation scores tend to be normal distribution, we can use the quartile method to calculate the $Z$-score and categorize the overall evaluation scores according to the $Z$-score. The specific steps are as follows.

Step 1: rank the comprehensive evaluation scores $z_{j}$ $(j=1, \ldots, n)$ by ascending sorting. The ranked results are shown in Table 5.

Step 2: the $Z$-score $Z_{j}$ of $z_{j}$ is calculated according to equation (13). From the comprehensive evaluation scores, find the values for a quarter of $z_{6}=0.027$, two quarters of $z_{11}=0.165$, and three quarters of $z_{16}=0.339$ of the population.

Step 3: the evaluation criteria $(\bar{Z}=-0.528$ and $\widehat{Z}=0.859$ ) are determined using equations (14) and (15). According to $\bar{Z}$ and $\widehat{Z}$, the $Z$-scores are divided into three categories, namely, "excellent" $\left(Z_{j}<\bar{Z}\right)$ for DMUs 2, 4, 6, 10, and 20; "ordinary" $\left(\bar{Z}<Z_{j}<\widehat{Z}\right)$ for DMUs $1,3,5,7,8,9,16,17,18$, and 21 ; and "pending improvement" $\left(\widehat{Z}<Z_{j}\right)$ for DMUs $11,12,13,14,15$, and 19. The computed results are shown in Table 5 .

The next steps involve categorizing all of the DMUs using $\theta^{g}, \theta^{b}, \theta^{\prime g}$, and $\theta^{\prime b}$ in Table 3 . The results are shown in Figure 5. A comprehensive feature analysis of DMUs is performed according to the category assessment standard given in Table 1. Table 6 gives the location of each DMU.

Table 6 and Figure 5 show that the "excellent" DMUs in Table 5 are mostly distributed in the "excellent" area of Table 6, especially DMU ${ }_{10}$, which is "exemplary" in both the DEA evaluation and inverted-DEA evaluation because the input/output scale is small compared to that of other DMUs. Additionally, the two undesirable outputs (sulfur dioxide emissions and industrial solid waste emissions) are small (the sulfur dioxide emissions are 0 ). The "pending improvement" DMUs in Table 5 are mostly distributed in the 


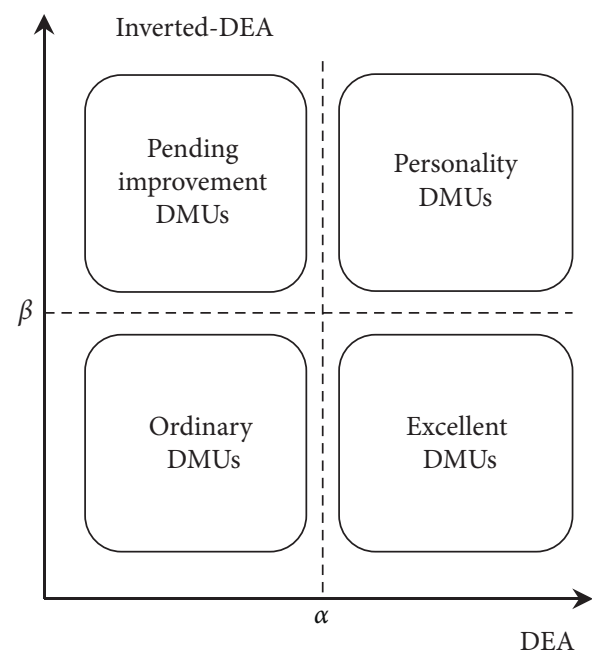

(a)

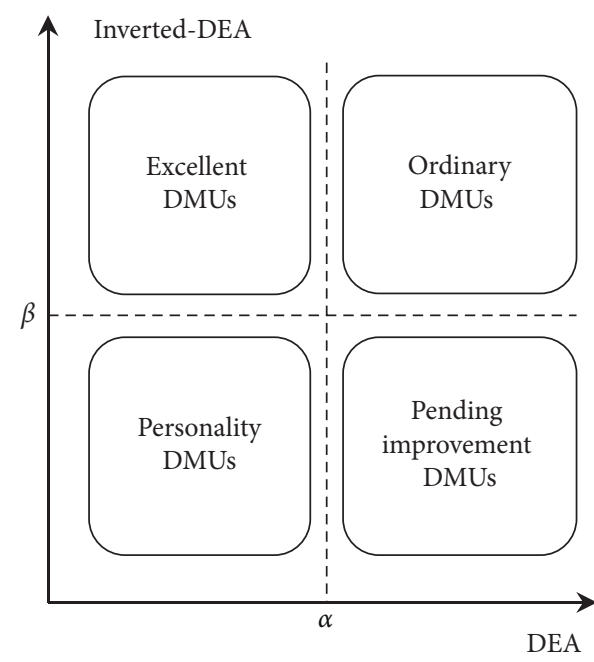

(b)

Figure 3: Category analysis of desirable and undesirable outputs. (a) DMUs with desirable outputs. (b) DMUs with undesirable outputs.

TABLE 2: Input and output data of 21 industrial parks.

\begin{tabular}{|c|c|c|c|c|c|c|c|c|c|}
\hline \multirow[b]{2}{*}{ DMU } & \multicolumn{4}{|c|}{ Inputs } & \multicolumn{2}{|c|}{ Desirable outputs } & \multicolumn{3}{|c|}{ Undesirable outputs } \\
\hline & $\begin{array}{l}X_{1} \text { million } \\
\text { metric tons }\end{array}$ & $\begin{array}{l}X_{2} \text { million } \\
\text { metric tons }\end{array}$ & $\begin{array}{c}X_{3} \text { million } \\
\text { hectares }\end{array}$ & $\begin{array}{c}X_{4} \\
\left(108 \mathrm{~m}^{3}\right)\end{array}$ & $\begin{array}{c}D_{1} \text { ten } \\
\text { thousand yuan/ } \\
\text { ton }\end{array}$ & $\begin{array}{l}D_{2} 100 \\
\text { million }\end{array}$ & $\begin{array}{l}U_{1} \text { million } \\
\text { metric tons }\end{array}$ & $\begin{array}{l}U_{2} \text { million } \\
\text { metric tons }\end{array}$ & $\begin{array}{c}U_{3} \text { million } \\
\text { cubic meters }\end{array}$ \\
\hline $\mathrm{DMU}_{1}$ & 2.1953 & 344.68 & 0.21 & 4.43 & 1.68 & 368.81 & 0.98 & 0.2302 & 4.2482 \\
\hline $\mathrm{DMU}_{2}$ & 1.5732 & 137.77 & 0.51 & 0.35 & 6.13 & 964.37 & 0.00 & 0.0890 & 13.0000 \\
\hline $\mathrm{DMU}_{3}$ & 21.5504 & 367.70 & 0.31 & 0.35 & 0.12 & 247.83 & 1.14 & 0.0103 & 9.8010 \\
\hline $\mathrm{DMU}_{4}$ & 1.4433 & 27.76 & 0.10 & 0.01 & 0.50 & 72.16 & 0.08 & 0.0000 & 0.1875 \\
\hline $\mathrm{DMU}_{5}$ & 5.4718 & 99.43 & 0.16 & 0.11 & 1.49 & 815.29 & 0.29 & 0.1629 & 4.6500 \\
\hline $\mathrm{DMU}_{6}$ & 0.6564 & 97.25 & 0.08 & 0.36 & 2.00 & 131.29 & 0.08 & 0.0004 & 0.9000 \\
\hline $\mathrm{DMU}_{7}$ & 1.5244 & 354.61 & 0.29 & 0.31 & 3.28 & 500.00 & 0.38 & 0.0000 & 15.0000 \\
\hline $\mathrm{DMU}_{8}$ & 12.6172 & 283.17 & 0.05 & 0.14 & 0.25 & 312.91 & 1.06 & 0.0000 & 8.5100 \\
\hline $\mathrm{DMU}_{9}$ & 6.6667 & 455.37 & 0.25 & 0.71 & 0.38 & 250.00 & 0.25 & 0.11000 & 2.8796 \\
\hline $\mathrm{DMU}_{10}$ & 0.2635 & 71.66 & 0.80 & 0.36 & 8.35 & 220.00 & 0.01 & 0.0000 & 1.5504 \\
\hline $\mathrm{DMU}_{11}$ & 155.0398 & 1903.78 & 1.32 & 38.42 & 0.14 & 211.30 & 0.03 & 1.3 .90 & 24.3110 \\
\hline $\mathrm{DMU}_{12}$ & 4.0597 & 937.16 & 0.33 & 1.24 & 0.84 & 340.00 & 0.96 & 3.4500 & 21.2600 \\
\hline $\mathrm{DMU}_{13}$ & 1.0072 & 58.19 & 0.11 & 0.40 & 0.78 & 78.56 & 0.33 & 0.1200 & 0.7930 \\
\hline $\mathrm{DMU}_{14}$ & 1.83114 & 606.38 & 0.99 & 1.87 & 0.40 & 739.78 & 2.26 & 6.4200 & 55.1000 \\
\hline $\mathrm{DMU}_{15}$ & 12.3134 & 1155.87 & 3.71 & 0.38 & 0.27 & 330.00 & 5.21 & 0.0000 & 3.9000 \\
\hline $\mathrm{DMU}_{16}$ & 50.0000 & 1398.60 & 2.74 & 3.20 & 0.40 & 2000.00 & 1.80 & 0.0000 & 14.0000 \\
\hline $\mathrm{DMU}_{17}$ & 4.6512 & 393.18 & 1.50 & 1.20 & 6.45 & 3000.00 & 0.00 & 0.5600 & 29.0000 \\
\hline $\mathrm{DMU}_{18}$ & 6.5574 & 400.00 & 0.36 & 0.60 & 0.61 & 400.00 & 0.40 & 0.0500 & 18.0000 \\
\hline $\mathrm{DMU}_{19}$ & 3.9859 & 15.87 & 0.16 & 0.04 & 0.51 & 203.28 & 0.08 & 0.3368 & 1.9916 \\
\hline $\mathrm{DMU}_{20}$ & 0.4836 & 36.29 & 0.50 & 1.49 & 9.56 & 462.28 & 0.05 & 0.0020 & 6.3875 \\
\hline $\mathrm{DMU}_{21}$ & 48.0531 & 4395.10 & 1.89 & 0.41 & 1.50 & 720.70 & 0.08 & 0.0500 & 3.6000 \\
\hline
\end{tabular}

"pending improvement" area of Table 6. In particular, $\mathrm{DMU}_{15}$ is "pending improvement" in terms of evaluation of the desirable outputs of DEA and undesirable outputs of inverted-DEA because the input indexes (energy and land) are high (in comparison with the average) and the desirable output indexes (resource output rate and the total production value) are relatively low; moreover, the undesirable output indexes (industrial solid waste emissions and industrial wastewater discharge) are relatively high. Additionally, $\mathrm{DMU}_{3}$ is in the "ordinary" area in terms of the desirable output evaluation based on DEA and undesirable output evaluation based on inverted-DEA, and it is also in the middle position in the rankings in Table 5. For $\mathrm{DMU}_{3}$, in addition to the high resource input (compared to the 
TABLE 3: Efficiency and inefficiency scores of 21 industrial parks.

\begin{tabular}{lcccc}
\hline \multirow{2}{*}{ DMU } & \multicolumn{2}{c}{ Desirable output } & \multicolumn{2}{c}{ Undesirable output } \\
& Efficiency score $\left(\theta^{g}\right.$-rank 1$)$ & Inefficiency score $\left(\theta^{\prime g}\right.$-rank 2$)$ & Efficiency score $\left(\theta^{b}\right.$-rank 3) & Inefficiency score $\left(\theta^{\prime b}\right.$-rank 4$)$ \\
\hline DMU $_{1}$ & 0.671 & 0.104 & 1.000 & 0.106 \\
DMU $_{2}$ & 1.000 & 0.048 & 1.000 & 1.000 \\
DMU $_{3}$ & 0.153 & 0.255 & 0.789 & 0.524 \\
DMU $_{4}$ & 1.000 & 0.133 & 0.687 & 0.650 \\
DMU $_{5}$ & 1.000 & 0.021 & 0.918 & 0.036 \\
DMU $_{6}$ & 1.000 & 0.089 & 0.389 & 0.260 \\
DMU $_{7}$ & 0.857 & 0.085 & 1.000 & 0.151 \\
DMU $_{8}$ & 1.000 & 0.100 & 1.000 & 0.429 \\
DMU $_{9}$ & 0.230 & 0.202 & 0.258 & 0.097 \\
DMU $_{10}$ & 1.000 & 0.327 & 0.525 & 1.000 \\
DMU $_{11}$ & 0.030 & 1.000 & 0.247 & 1.000 \\
DMU $_{12}$ & 0.356 & 0.306 & 1.000 & 0.017 \\
DMU $_{13}$ & 0.373 & 0.144 & 1.000 & 0.028 \\
DMU $_{14}$ & 0.212 & 0.202 & 1.000 & 0.011 \\
DMU $_{15}$ & 0.154 & 1.000 & 1.000 & 0.086 \\
DMU $_{16}$ & 0.208 & 0.539 & 0.294 & 1.000 \\
DMU $_{17}$ & 1.000 & 0.045 & 0.851 & 0.545 \\
MMU $_{18}$ & 0.317 & 0.125 & 0.874 & 0.116 \\
DMU $_{19}$ & 1.000 & 0.081 & 1.000 & 0.056 \\
DMU $_{20}$ & 1.000 & 0.104 & 1.000 & 0.147 \\
DMU $_{21}$ & 0.237 & 0.677 & 0.803 & 1.000 \\
\hline
\end{tabular}

TABLE 4: The comprehensive evaluation scores.

\begin{tabular}{|c|c|c|}
\hline DMU & Comprehensive evaluation scores $\left(z_{j}\right)$ & Rank $(j)$ \\
\hline $\mathrm{DMU}_{1}$ & 0.042 & 7 \\
\hline $\mathrm{DMU}_{2}$ & 0.488 & 20 \\
\hline $\mathrm{DMU}_{3}$ & 0.165 & 11 \\
\hline $\mathrm{DMU}_{4}$ & 0.449 & 19 \\
\hline $\mathrm{DMU}_{5}$ & 0.059 & 8 \\
\hline $\mathrm{DMU}_{6}$ & 0.416 & 18 \\
\hline $\mathrm{DMU}_{7}$ & 0.067 & 9 \\
\hline $\mathrm{DMU}_{8}$ & 0.203 & 12 \\
\hline $\mathrm{DMU}_{9}$ & 0.215 & 13 \\
\hline $\mathrm{DMU}_{10}$ & 0.617 & 21 \\
\hline $\mathrm{DMU}_{11}$ & 0.013 & 5 \\
\hline $\mathrm{DMU}_{12}$ & 0.005 & 3 \\
\hline $\mathrm{DMU}_{13}$ & 0.009 & 4 \\
\hline $\mathrm{DMU}_{14}$ & 0.003 & 1 \\
\hline $\mathrm{DMU}_{15}$ & 0.003 & 2 \\
\hline $\mathrm{DMU}_{16}$ & 0.287 & 15 \\
\hline $\mathrm{DMU}_{17}$ & 0.339 & 16 \\
\hline $\mathrm{DMU}_{18}$ & 0.072 & 10 \\
\hline $\mathrm{DMU}_{19}$ & 0.027 & 6 \\
\hline $\mathrm{DMU}_{20}$ & 0.380 & 17 \\
\hline $\mathrm{DMU}_{21}$ & 0.260 & 14 \\
\hline
\end{tabular}

The comprehensive evaluation scores in Table 4 indicate that the proposed models increase the discrimination ability in this empirical study.

average), the three input indexes (energy, land, and water resources) are generally low, and the two desirable output indexes (resource output rate and total production value) are relatively low; moreover, the three undesirable output indexes are relatively high, except for sulfur dioxide emissions. The other two indexes (industrial solid waste emissions and industrial wastewater discharge) of $\mathrm{DMU}_{3}$ are low, especially industrial solid waste emissions (0.0103), for which the value is much lower than the average (0.6148).

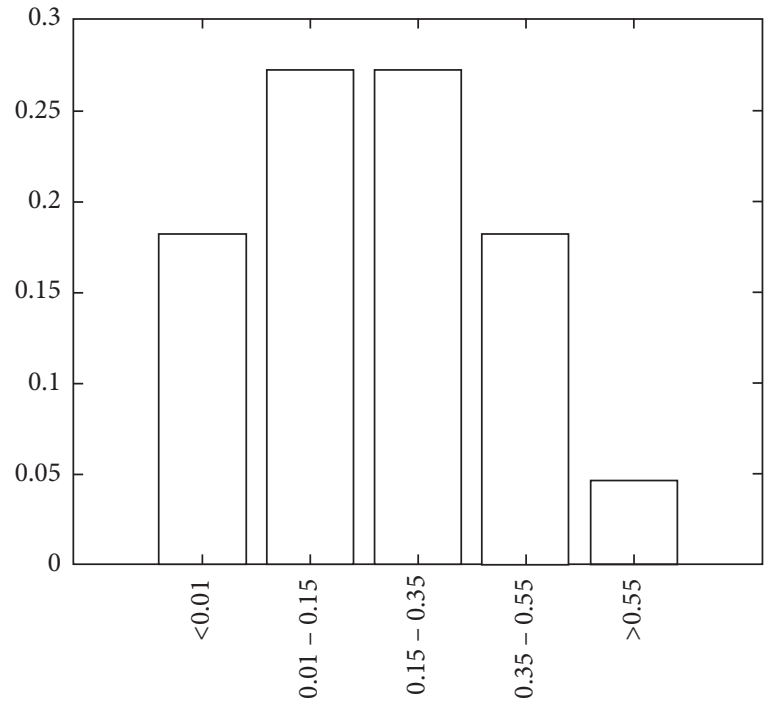

FIGURE 4: The distribution of the comprehensive evaluation scores.

It is also worth noting that $\mathrm{DMU}_{11}$ and $\mathrm{DMU}_{19}$ are "pending improvement" DMUs in Table 5. In Table 6, $\mathrm{DMU}_{19}$ is in the "excellent" area for desirable outputs based on DEA and the "pending improvement" area for undesirable outputs based on inverted-DEA. The scenario for $\mathrm{DMU}_{11}$ is the opposite of that for $\mathrm{DMU}_{19}$. The four input indexes of $\mathrm{DMU}_{11}$ are higher than the average, and the desirable output indexes are lower than the average, so the efficiency score of inverted-DEA is high (1.00), and the efficiency score of DEA is very low (0.030). For the undesirable output indexes, except for higher sulfur dioxide emissions (compared with the average), other industrial solid waste emissions and industrial wastewater discharge are low, so the efficiency score of DEA of $D^{2} U_{11}$ is high 
TABle 5: The Z-scores of DMUs.

\begin{tabular}{|c|c|c|}
\hline $\mathrm{DMU}$ & Comprehensive evaluation scores $\left(z_{j}\right)$ & $Z$-score $\left(Z_{j}\right)$ \\
\hline $\mathrm{DMU}_{14}$ & 0.003 & -0.702 \\
\hline $\mathrm{DMU}_{15}$ & 0.003 & -0.700 \\
\hline $\mathrm{DMU}_{12}$ & 0.005 & -0.695 \\
\hline $\mathrm{DMU}_{13}$ & 0.009 & -0.677 \\
\hline $\mathrm{DMU}_{11}$ & 0.013 & -0.657 \\
\hline $\mathrm{DMU}_{19}$ & 0.027 & -0.598 \\
\hline $\mathrm{DMU}_{1}$ & 0.042 & -0.535 \\
\hline $\mathrm{DMU}_{5}$ & 0.059 & -0.461 \\
\hline $\mathrm{DMU}_{7}$ & 0.067 & -0.425 \\
\hline $\mathrm{DMU}_{18}$ & 0.072 & -0.403 \\
\hline $\mathrm{DMU}_{3}$ & 0.165 & 0 \\
\hline $\mathrm{DMU}_{8}$ & 0.203 & 0.166 \\
\hline $\mathrm{DMU}_{9}$ & 0.215 & 0.218 \\
\hline $\mathrm{DMU}_{21}$ & 0.260 & 0.409 \\
\hline $\mathrm{DMU}_{16}$ & 0.287 & 0.521 \\
\hline $\mathrm{DMU}_{17}$ & 0.339 & 0.751 \\
\hline $\mathrm{DMU}_{20}$ & 0.380 & 0.931 \\
\hline $\mathrm{DMU}_{6}$ & 0.416 & 1.085 \\
\hline $\mathrm{DMU}_{4}$ & 0.449 & 1.229 \\
\hline $\mathrm{DMU}_{2}$ & 0.488 & 1.396 \\
\hline $\mathrm{DMU}_{10}$ & 0.617 & 1.954 \\
\hline
\end{tabular}

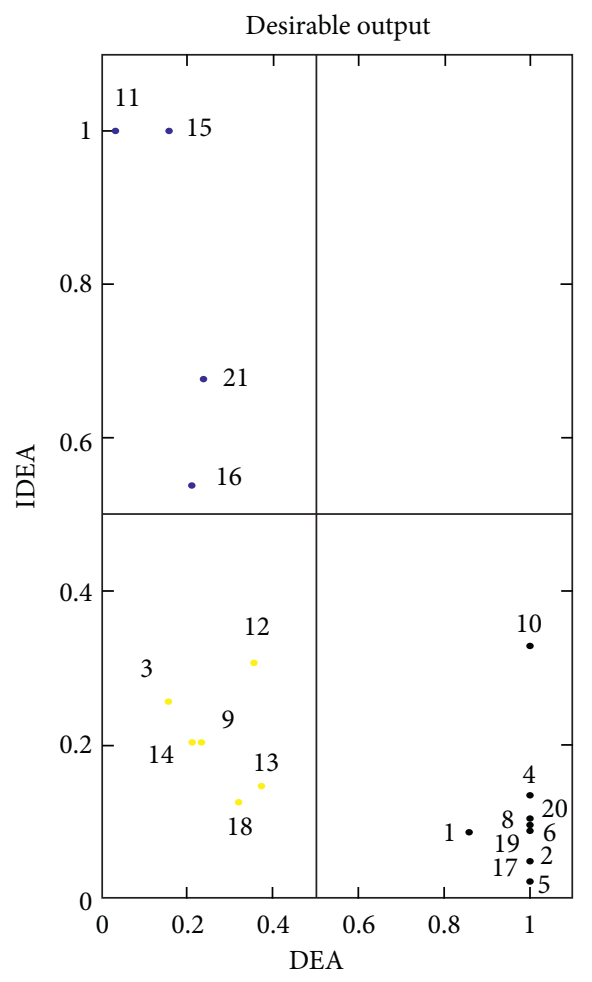

(a)

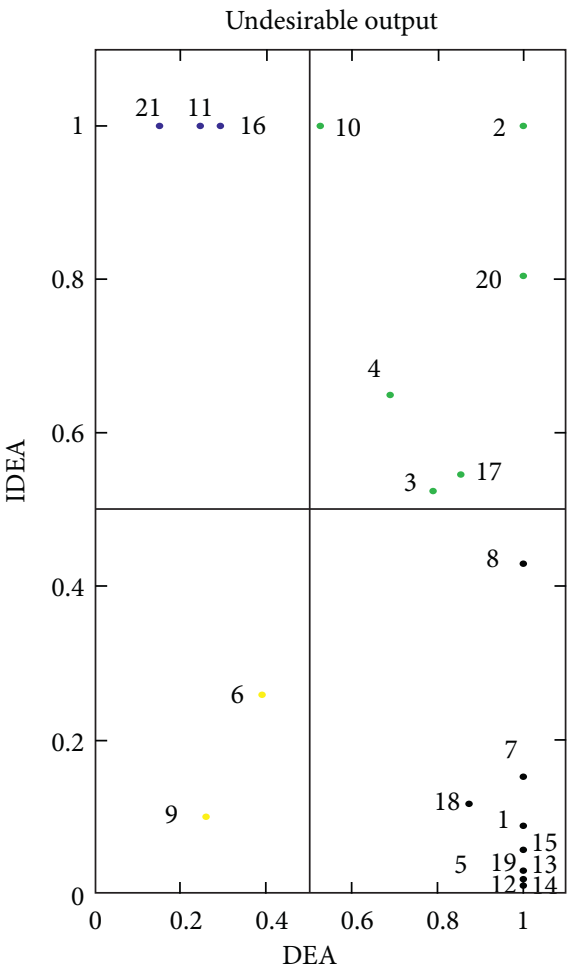

(b)

FIGURE 5: Category analysis of DMUs with desirable outputs and undesirable outputs. (a) DMUs with desirable outputs. (b) DMUs with undesirable outputs.

(1.00), and the efficiency score of inverted-DEA is deficient $(0.056)$. Thus, $\mathrm{DMU}_{11}$ should reduce the related inputs according to these findings and increase the related desirable outputs; specifically, reducing the level of sulfur dioxide emissions should be prioritised. The four input indexes of $\mathrm{DMU}_{19}$ are lower than the average values, and the output indexes, whether desirable or undesirable, are lower than the average index values, so the efficiency scores of DEA are all 1 and the efficiency scores of inverted-DEA are 0.081 and 0.056 (lower than the 
TABLE 6: Comprehensive feature analysis of DMUs.

\begin{tabular}{|c|c|c|}
\hline $\begin{array}{l}\text { Category analysis of } \\
\text { DMUs }\end{array}$ & DMUs with desirable output & DMUs with undesirable output \\
\hline Excellent DMUs & $\begin{array}{c}\mathrm{DMU}_{1}, \mathrm{DMU}_{2}, \mathrm{DMU}_{4}, \mathrm{DMU}_{5}, \mathrm{DMU}_{6}, \mathrm{DMU}_{7}, \mathrm{DMU}_{8}, \\
\mathrm{DMU}_{10}, \mathrm{DMU}_{17}, \mathrm{DMU}_{19}, \mathrm{DMU}_{20}\end{array}$ & $\mathrm{DMU}_{10}, \mathrm{DMU}_{11}, \mathrm{DMU}_{16}, \mathrm{DMU}_{21}$ \\
\hline Personality DMUs & - & $\mathrm{DMU}_{6}, \mathrm{DMU}_{9}$ \\
\hline Ordinary DMUs & $\mathrm{DMU}_{3}, \mathrm{DMU}_{9}, \mathrm{DMU}_{12}, \mathrm{DMU}_{13}, \mathrm{DMU}_{14}, \mathrm{DMU}_{18}$ & $\mathrm{DMU}_{2}, \mathrm{DMU}_{3}, \mathrm{DMU}_{4}, \mathrm{DMU}_{8}, \mathrm{DMU}_{17}, \mathrm{DMU}_{20}$ \\
\hline $\begin{array}{l}\text { Pending improvement } \\
\text { DMUs }\end{array}$ & $\mathrm{DMU}_{11}, \mathrm{DMU}_{15}, \mathrm{DMU}_{16}, \mathrm{DMU}_{21}$ & $\begin{array}{c}\mathrm{DMU}_{1}, \mathrm{DMU}_{5}, \mathrm{DMU}_{7}, \mathrm{DMU}_{12}, \mathrm{DMU}_{13}, \mathrm{DMU}_{14}, \\
\mathrm{DMU}_{15}, \mathrm{DMU}_{18}, \mathrm{DMU}_{19}\end{array}$ \\
\hline
\end{tabular}

average). Although the three undesirable output indexes of $\mathrm{DMU}_{19}$ are lower than the average values, the values of the desirable output indexes are relatively high. For $\mathrm{DMU}_{19}$, while improving the inputs, efforts should be made to improve the desirable output indexes and reduce the undesirable outputs.

\section{Conclusion}

Based on the concept of using inverted-DEA to process DMUs with undesirable outputs, this paper proposes a method for the comprehensive evaluation of DMUs with both desired and undesired outputs using a DEA model and an inverted-DEA model. This approach enhances the recognition capabilities of DEA. The DMUs are sorted and categorized by the quartile method. Based on this category analysis, combined with the efficiency scores of DEA and inverted-DEA, the overall rank of DMUs is characterized. Finally, this paper uses the proposed method to evaluate the efficiency of 21 industrial parks in China in 2017, and the characteristics of some individual industrial parks are evaluated based on the input and output indicators. The findings highlight the advantages of the proposed method, which provides an improved discrimination evaluation approach compared to existing methods by utilizing DEA and inverted-DEA.

\section{Data Availability}

The data used to support the findings of this study are available from the corresponding author upon request.

\section{Additional Points}

Highlights. (i) A new performance evaluation model based on both DEA and inverted-DEA is developed to improve the recognition capability of DEA. (ii) An effective method is proposed to address DMUs with undesirable outputs based on inverted-DEA. (iii) The quartile method is used to categorize the ranked DMUs. (iv) The DMUs are categorized using the efficiency score of DEA and the inefficiency score of inverted-DEA. (v) The proposed method is validated based on an empirical analysis of 21 industrial parks in China.

\section{Conflicts of Interest}

The authors declare no conflicts of interest.

\section{Acknowledgments}

The research was supported by the National Key R\&D Program of China (2018YFF0215701), the Qin Xin Talents Cultivation Program, BISTU (QXTCP C201907), and the General Project of Social Science Program of Beijing Municipal Education Commission (SM201811232002).

\section{References}

[1] A. Charnes, W. W. Cooper, and E. Rhodes, "Measuring the efficiency of decision making units," European Journal of Operational Research, vol. 2, no. 6, pp. 429-444, 1978.

[2] Z. Li, D. Tang, M. Han, and J. B. Brandon, "Comprehensive evaluation of regional sustainable development based on data envelopment analysis," Sustainability, vol. 10, no. 11, pp. 1-18, 2018.

[3] R. Allen, A. Athanassopoulos, R. G. Dyson, and E. Thanassoulis, "Weights restrictions and value judgments in data envelopment analysis: evolution, development and future directions," Annals of Operations Research, vol. 73, pp. 13-34, 1997.

[4] P. Andersen and N. C. Petersen, "A procedure for ranking efficient units in data envelopment analysis," Management Science, vol. 39, no. 10, pp. 1261-1264, 1993.

[5] R. D. Banker and J. L. Gillord, A Relative Efficiency Model for the Evaluation of Public Health Nurse Productivity, Carnegie Mellon University, Pittsburgh, PA, USA, 1988.

[6] R. D. Banker and H. Chang, "The super-efficiency procedure for outlier identification, not for ranking efficient units," European Journal of Operational Research, vol. 175, no. 2, pp. 1311-1320, 2006.

[7] T. R. Sexton, R. H. Silkman, and A. J. Hogan, "Data envelopment analysis: critique and extensions," in Measuring Efficiency: An Assessment of Data Envelopment Analysis, R. H. Silkman, Ed., pp. 73-105, Jossey-Bass, San Francisco, CA, USA, 1986.

[8] J. R. Doyle and R. Green, "Efficiency and cross-efficiency in data envelopment analysis: derivatives, meanings and uses," Journal of the Operational Research Society, vol. 45, no. 5, pp. 67-78, 1994.

[9] A. Amirteimoori, "DEA efficiency analysis: efficient and antiefficient frontier," Applied Mathematics and Computation, vol. 186, no. 1, pp. 10-16, 2007.

[10] D. Q. Zhang, L. Qi, X. X. Li, and W. B. Liu, DEA Analysis Based on Both Efficient and Anti-Efficient Frontiers, University of Kent, Canterbury, UK, 2007.

[11] J. Cao, G. H. Chen, M. Khoveyni, R. Eslami, and G. L. Yang, "Specification of a performance indicator using the evidentialreasoning approach," Knowledge-Based Systems, vol. 92, no. 1, pp. 38-50, 2016.

[12] P. Zhou, K. L. Poh, and B. W. Ang, "A non-radial DEA approach to measuring environmental performance," 
European Journal of Operational Research, vol. 178, no. 1, pp. 1-9, 2007.

[13] W. B. Liu, W. Meng, X. X. Li, and D. Q. Zhang, "DEA models with undesirable inputs and outputs," Annals of Operations Research, vol. 173, no. 1, pp. 177-194, 2010.

[14] W. B. Liu, D. Q. Zhang, W. Meng, X. X. Li, and F. Xu, "A study of DEA models without explicit inputs," Omega, vol. 39, no. 5, pp. 472-480, 2011.

[15] G. Yang, W. Shen, D. Zhang, and W. Liu, "Extended utility and DEA models without explicit input," Journal of the Operational Research Society, vol. 65, no. 8, pp. 1212-1220, 2014.

[16] W.-f. Shen, D.-q. Zhang, W.-b. Liu, and G.-l. Yang, "Increasing discrimination of DEA evaluation by utilizing distances to anti-efficient frontiers," Computers \& Operations Research, vol. 75, pp. 163-173, 2016.

[17] T. Entani, Y. Maeda, and H. Tanaka, "Dual models of interval DEA and its extension to interval data," European Journal of Operational Research, vol. 136, no. 1, pp. 32-45, 2002.

[18] Y. Yamada, T. Matsui, and M. Sugiyama, "An inefficiency measurement method for management systems," Journal of the Operations Research Society of Japan, vol. 37, no. 2, pp. 158-168, 1994.

[19] T. C. Koopmans, "Analysis of production as an efficient combination of activities," in Activity Analysis of Production and Allocation, Cowles Commission, pp. 33-97, Wiley, New York, NY, USA, 1951.

[20] L. M. Seiford and J. Zhu, "Modeling undesirable factors in efficiency evaluation," European Journal of Operational Research, vol. 142, no. 1, pp. 16-20, 2002.

[21] W. B. Liu, W. Meng, X. X. Li, and D. Q. Zhang, "DEA models with undesirable inputs and outputs," Annals of Operations Research, vol. 73, no. 1, pp. 7-194, 2010.

[22] A. I. Ali and L. M. Seiford, "Translation invariance in data envelopment analysis," Operations Research Letters, vol. 9, no. 6, pp. 403-405, 1990.

[23] W. B. Liu, J. Sharp, and Z. M. Wu, "Preference, production and performance in data envelopment analysis," Annals of Operations Research, vol. 145, pp. 105-127, 1999.

[24] R. Faere, S. Grosskopf, C. A. K. Lovell, and C. Pasurka, "Multilateral productivity comparisons when some outputs are undesirable: a nonparametric approach," The Review of Economics and Statistics, vol. 71, no. 1, pp. 90-98, 1989. 